\title{
Recombinant Porcine Lactoferrin Expressed in the Milk of Transgenic Mice Enhances Offspring Growth Performance
}

\author{
Shinn-Chin Wu, ${ }^{\dagger,}$ Hsiao-Ling Chen, ${ }^{\dagger, \#}$ Chin-Ching Yen,,$\stackrel{\S}{\S}$ Meng-Fu Kuo,, \\ Tien-Shum Yang, ${ }^{\perp}$ Shim-Rong Wang, ${ }^{\perp}$ Chung-Nan Weng, ${ }^{\perp}$ \\ Chuan-Mu Chen, $*$, and Winston T. K. Cheng*,*
}

\begin{abstract}
Department of Animal Science and Technology, National Taiwan University, Taipei 106, Taiwan; Department of Molecular Biotechnology, Da-Yeh University, Changhwa 515, Taiwan; Department of Life Sciences, National Chung-Hsing University, Taichung 402, Taiwan; China Medical University Hospital, Taichung 404, Taiwan; and Animal Technology, Institute Taiwan, Miaoli,
\end{abstract}

P.O. Box 23, Taiwan

\begin{abstract}
The European Commission has proposed a permanent ban on the use of antibiotics as an ingredient in animal feed to promote growth. Lactoferrin is a globular multifunctional protein that has been shown to play a role in iron absorption and to have antimicrobial and anti-inflammatory activities. Therefore, lactoferrin may serve as a nontherapeutic alternative to antibiotics in livestock husbandry. As a pilot study toward this goal, transgenic mice have been generated harboring a porcine lactoferrin (pLF) gene driven by the mammary gland-specific promoter of the bovine $\alpha$-lactalbumin $(\alpha L A)$ gene. The $\alpha \mathrm{LA}-\mathrm{pLF}$ hybrid gene was confirmed to have been successfully integrated and transmitted stably through the germ-line in 9 ( 5 females and 4 males) of 14 transgenic founders. In the female progenies of six lines analyzed, the transgene copy numbers ranged from 1 to 20 with 1-4 integration sites. Significant levels of pLF protein in milk ranging from 40 to $106 \mu \mathrm{g} / \mathrm{mL}$ with physical characteristics similar to those of native pLF in sow's milk were achieved in three of the transgenic lines obtained. Tissue- and stage-specific pLF expressions were restricted to the mammary gland of the transgenic female mice during lactation. It was further demonstrated that the growth performance of animal pups is enhanced by directly feeding the genetically engineered milk containing enriched pLF protein in transgenic mice. Furthermore, this enhanced growth performance in suckling mice was proportional to the concentration of pLF present in milk.
\end{abstract}

KEYWORDS: Porcine lactoferrin; transgenic mice; mammary gland; growth rate

\section{INTRODUCTION}

Manipulation of milk composition by transgenesis has mainly focused on the mammary gland as a bioreactor to produce pharmaceuticals. However, genetic manipulation of milk for nutritional, physiochemical, or technological purposes is another important aim of this research. Transgenic animals that express foreign proteins in their mammary glands have been engineered by inserting promoters of milk protein genes such as $\alpha$-casein (1), $\beta$-casein (2), whey acidic protein (3), $\alpha$-lactalbumin (4), and $\beta$-lactoglobulin (5). Most of these regulatory sequences have been demonstrated to be successful in controlling mammary gland-specific expression of exogenic proteins in nano- to minigram levels.

* Corresponding authors [(W.T.K.C.) telephone 886-2-2733-7180, fax 886-2-2732-4070, e-mail wtkcheng@ @ tu.edu.tw; (C.-M.C.) telephone 8864-2285 6309, fax 886-4-2287 4740, e-mail chchen1@ dragon.nchu.edu.tw].

S.-C.W. and H.-L. C. contributed equally to this work.

National Taiwan University.

\# Da-Yeh University.

$\S$ National Chung Hsing University.

"China Medical University Hospital.

$\perp$ Animal Technology Institute Taiwan.
Lactoferrin (LF) is a positively charged glycoprotein found in the milk of many mammals, including human beings, monkeys, cattle, and swine. The protein consists of a single polypeptide with two iron-binding domains; its molecular mass is estimated to range from 72 to $85 \mathrm{kDa}$ depending on the mammalian species. LF has been documented to have antimicrobial properties, to be an antioxidant, to promote growth of lymphocytes, to regulate iron absorption, and even to act as a transcription activator $(6-8)$. Lactoferrin is a cationic protein exhibiting bacteriostatic and bactericidal effects that contribute to both systemic and mucosal immune defense (9). For example, it serves as a scavenger of free iron, thereby depriving microorganisms of this essential nutrient. LF destabilizes the outer membrane of Gram-negative bacteria by stimulating the release of lipopolysaccharides (LPS) from their cell walls, which depolarizes the cytoplasmic membrane (10). In the subinhibitory concentration of lactoferrin, it also acts an important component of innate immunity by preventing bacterial biofilm development (11). 
Table 1. Oligonucleotide Primer Sets Used for the Construction and Detection of $\alpha$ LA-pLF Transgene in Transgenic Mice

\begin{tabular}{|c|c|c|c|}
\hline primer set ${ }^{a}$ & oligonucleotide sequence $\left(5^{\prime}-3^{\prime}\right)$ & $\begin{array}{c}T_{\mathrm{m}} \\
\left({ }^{\circ} \mathrm{C}\right)\end{array}$ & $\begin{array}{l}\text { PCR } \\
\text { product } \\
\text { size (bp) }\end{array}$ \\
\hline $\begin{array}{l}\text { paLA-F(+) } \\
\text { paLA-R(-) }\end{array}$ & $\begin{array}{l}\text { (A) Bovine } \alpha \text { LA Promoter Region } \\
\text { 5'-TCGCGTAGAATCGATTCATGT-3' } \\
\text { 5'-CCGCGGAGCCTGGGTGGCAT-3' }\end{array}$ & $\begin{array}{l}60 \\
68\end{array}$ & 2047 \\
\hline $\begin{array}{l}\text { pLF-Sacll(+) } \\
\text { pLF-Pstl(-) }\end{array}$ & $\begin{aligned} & \text { (B) Porcine LF cDNA Coding Region } \\
& \text { 5'-CCGCGGGCCCCTAAGAAAGG-3' } \\
& \text { 5'-CTGCAGTCAGGTAGCGATGGC-3' }\end{aligned}$ & $\begin{array}{l}68 \\
68\end{array}$ & 2004 \\
\hline $\begin{array}{l}\text { paLA-124(+) } \\
\text { pLF-326(-) }\end{array}$ & $\begin{array}{l}\text { (C) } \alpha \text { LA-pLF Transgene Junction } \\
\text { 5'-CTCTCTTGTCATCCTCTTCC-3'3 } \\
\text { 5'-AGAAGCCCTCCTTATGCAGA-3' }\end{array}$ & $\begin{array}{l}60 \\
60\end{array}$ & 450 \\
\hline
\end{tabular}

\footnotetext{
${ }^{a}$ Parentheses following each primer name: $(+)$ upstream primer; $(-)$ downstream primer. ${ }^{b}$ Nucleotide sequences with underscores indicate the created restriction enzyme cutting sites within primers.
}

Porcine lactoferrin (pLF) is secreted in the colostrum at a higher level than other mammalian lactoferrins $(7,12)$. The structure and functions of bovine and human LF have been well characterized (13-15), but little is known about porcine LF. In a previous study, we generated an expression system using a recombinant methylotrophic yeast, Pichia pastoris, which harbored the $\mathrm{pLF}$ gene driven by the inducible promoter of the alcohol oxidase 1 gene $(A O X 1)$ and the yeast $\alpha$-mating factor signal peptide (7). Significant levels of secreted pLF were achieved in culture medium of the yeast transformants. The recombinant $\mathrm{pLF}$ was found to be similar in glycosylation pattern and antimicrobial function to natural LF derived from sow's milk (7). We also defined a 20-residue porcine lactoferricin (LFcin P-20) in the porcine LF $\mathrm{N}$ terminus, which displayed antimicrobial activity against Escherichia coli, Staphyloccocus aureus, and Candida albicans. Its bactericidal activity was 4 times more effective than that of human lactoferricin (16). It has been demonstrated that piglets that consume sufficient colostral milk exhibit enhanced resistance to diarrhea, respiratory tract infections, infection-induced wheezing, and anemia after weaning (17-19). Therefore, we hypothesize that pLF may play an important role in antimicrobial action, immunomodulation, and iron-binding functions when piglets are raised in a poor growing environment.

In animal husbandry, it is thought that supplementing the diet of neonatal piglets with pLF may decrease mortality rates of piglets due to diarrhea and anemia by rendering them more resistance to common infectious agents (17). Transgenic animals expressing the LF protein in the mammary gland and secreting high levels of LF in the milk may be generated to produce a whole new herd of diarrhea- and anemia-resistant piglets with better growth performance and commercial value. In this study, we have generated transgenic mice harboring the pLF gene driven by the mammary gland-specific promoter of the bovine $\alpha$-lactalbumin gene. Significant levels of pLF were achieved in some of the transgenic lines obtained. Here we describe the characterization of pLF secreted in milk of transgenic mice and the growth performance in 10 generations of their offspring.

\section{MATERIALS AND METHODS}

Transgene Construction and Transgenic Mouse Production. For the construction of a mammary gland-specific expression vector, we generated a $2.0 \mathrm{~kb}$ promoter sequence of bovine $\alpha$-lactalbumin $(\alpha \mathrm{LA})$ by PCR amplification using a primer set of p $\alpha \mathrm{LA}-\mathrm{F}(+) / \mathrm{R}(-)$ as listed in Table 1. This PCR product containing the entire $\alpha$ LA promoter and a 19-aa leader sequence (5'-ATG ATG TCC TTT GTC TCT CTG CTC
CTG GTA GGC ATC CTA TTC CAT GCC ACC CAG GCT-3') was inserted into the T-protruding pCR3 vector (Invitrogene, San Diego, CA). The resulting $7.0 \mathrm{~kb}$ plasmid was double digested with SacII and PstI and treated with calf intestinal phosphatase (Boehringer Mannheim, Indianapolis, IN). A cloned porcine LF full-length cDNA $(2.6 \mathrm{~kb})$ in the pGEM7 plasmid (20) was used to generate mature pLF coding sequences $(2.0 \mathrm{~kb})$ by PCR amplification using a primer set of pLF$\operatorname{SacII}(+)$ and pLF-Pst $(-)$ as described in Table 1. The amplified products were also double digested with SacII and PstI and then ligated into the pCR3- $\alpha$ LA vector. Several clones were screened with one clone containing the insert in the correct sequences selected, $\mathrm{pCR}-\alpha \mathrm{LA} / \mathrm{pLF}-$ 38 . The in-frame sequence from the $\alpha$ LA leader peptide through the pLF junction was determined using the Dye Terminator sequencing system (Applied Biosystems Inc., Foster, CA). The $4.5 \mathrm{~kb}$ transgene consisting of the $2.0 \mathrm{~kb}$ bovine $\alpha \mathrm{LA}$ promoter, $2.0 \mathrm{~kb}$ pLF cDNA, and $0.5 \mathrm{~kb}$ bovine growth hormone $(\mathrm{GH})$ gene polyadenosine signal sequence was separated from plasmid pCR- $\alpha$ LA/pLF-38 using AvrII and $\mathrm{XhoI}$ digestion and purified twice for microinjection by $\mathrm{CsCl}_{2}$ gradient ultracentrifugation method. The purified transgene was microinjected into the male pronuclei of fertilized eggs from superovulated female mice of the outbreed ICR strain and transferred to recipient pseudo-pregnant females as previously described (21). Animals were housed and handled according to guidelines of the Animal Care Committee of the National Chung Hsing University.

Transgene Detection by PCR Screening and Southern Blot Hybridization. The resulting pups were rapidly screened for the transgene by PCR amplification of tail DNA. Results were confirmed by Southern blot analysis. PCR was performed using one set of primers, p $\alpha$ LA-124(+) and pLF-326(-), as described in Table 1, which defined a $450 \mathrm{bp}$ region spanning the $\alpha \mathrm{LA}$ promoter and pLF cDNA junctional sequence. PCR was carried out in 30 cycles with denaturation at 94 ${ }^{\circ} \mathrm{C}$ for $30 \mathrm{~s}$, annealing at $55^{\circ} \mathrm{C}$ for $1 \mathrm{~min}$, and extension at $72{ }^{\circ} \mathrm{C}$ for $1 \mathrm{~min}$ in a thermal cycler (AG-9600; AcuGen Systems). The PCR products were then analyzed on a $1.5 \%$ agarose gel and visualized by ultraviolet transillumination. For Southern blot hybridization, $10 \mu \mathrm{g}$ of genomic DNA was digested with either DraI or BamHI restriction enzyme at $37{ }^{\circ} \mathrm{C}$ overnight, electrophoresed on an $0.8 \%$ agarose gel, and transferred to a Durose NC membrane (Stratagene, La Jolla, CA). A $S m a I-X h o I$ fragment of the $3^{\prime}$-end of the $\alpha \mathrm{LA}-\mathrm{pLF}$ transgene $(1.5 \mathrm{~kb})$ was used as a ${ }^{32} \mathrm{P}-\alpha-\mathrm{dCTP}$-labeled radioactive probe to hybridize the membrane. After the membranes had been washed under high stringency condition (22), blots were subjected to autoradiography for 3 days at $-20^{\circ} \mathrm{C}$.

Quantification of Transgene Insertion Copy by Slot-Blot Hybridization. Slot blot was prepared using standard protocol as described previously (23). Copy standards were prepared by mixing nontransgenic tail DNA $(10 \mu \mathrm{g})$ with a known amount of transgene plasmid DNA to produce transgene copy standards. Ten micrograms of genomic DNA samples was blotted onto the nitrocellulose membrane ImmobilonNC (Millipore, Bedford, MA) under vacuum by the Slot Blot Filtration Manifold (Hoefer Scientific Ins., San Francisco, CA). For DNA crosslinking, the filter was irradiated with UV using a UV-Stratalinker 1800 (Stratagene) with an energy output of $120 \mathrm{~mJ}$. DNA probe preparation, hybridization, and blot washing were carried out as described for the Southern blot assay. A panel of pCR- $\alpha$ LA/pLF-38 plasmid DNA was calculated and used as a standard for representation of different transgene insertion copies in one genome. After autoradiography, the filter was stripped and rehybridized with an $0.8 \mathrm{~kb}$ fragment of mouse $\beta$-actin gene probe that was used as an internal control (4). The $\alpha \mathrm{LA}$ pLF transgene integration copy was measured by a densitometer with a normalization based on the $\beta$-actin hybridization signal.

Western Blot and Enzyme-Linked Immunosorbent Assays (ELISAs) of pLF Secreting in the Milk. For collection of milk from transgenic mice, lactating female progenies obtained from the first generation (F1) to the fifth generation (F5) were injected intraperitoneally with oxytocin (China Chemical and Pharmaceutical Co., Taipei, Taiwan) at $0.01 \mathrm{IU} / \mathrm{g}$ of body weight. Milk was collected from nipples of anesthetized (avertin, $0.01 \mathrm{~mL} / \mathrm{g}$ of body weight) mice using a Pasteur pipet. The milk was diluted in an equal volume of $10 \mathrm{mM}$ Tris, 0.25 mM EDTA, $\mathrm{pH} 7.4$, and subjected to centrifugation at $12000 \mathrm{~g}$. The supernatant thus derived was used in $12 \%$ SDS-polyacrylamide gel 
electrophoresis (SDS-PAGE) and stained with Coomassie blue. Milk proteins were electrotransferred from the gel to a PVDF membrane according to our previous paper (24). The recombinant pLF protein was detected by a rabbit anti-pLF antibody (1:10000 dilutions) and a goat anti-rabbit IgG second antibody conjugated with horseradish peroxidase (HRP) (1:3000 dilutions; Santa Cruz Biotech. Inc., Santa Cruz, CA). The blot was then developed for $5 \mathrm{~min}$ at room temperature with developing buffer (12.5 mg of DAB in $0.5 \mathrm{~mL}$ of DMSO; $29 \mathrm{~mL}$ of PBS; $0.6 \mathrm{~mL}$ of $1 \% \mathrm{CoCl}_{2} ; 0.05 \mathrm{~mL}$ of $30 \% \mathrm{H}_{2} \mathrm{O}_{2}$ ). ELISA was performed using a rabbit anti-pLF antiserum and goat anti-rabbit immunoglobulin-HRP as described (20). pLF protein was detected using $o$-phenylenediamine (OPD; Sigma, St. Louis, MO) dissolved in citrate buffer ( $\mathrm{pH} 5.0$ ) in the presence of $0.01 \% \mathrm{H}_{2} \mathrm{O}_{2}$. Results were read using an ELISA microplate reader (Bio-Rad Lab., Hercules, CA) at $490 \mathrm{~nm}$.

Immuno-histochemical Staining of Mammary Gland in Lactating Mice. Freshly dissected mammary glands from transgenic and nontransgenic mice in the day 15 (D15) lactating stage were fixed in $10 \%$ paraformaldehyde as described in our previous paper (4). After dewaxing with xylene and dehydration, tissue sections $(5-10 \mu \mathrm{m})$ were stained with hematoxylin and eosin $\mathrm{B}$ red dyes. For immunohistochemical staining, a rabbit anti-pLF polyclonal antibody was diluted $1: 50$ [1\% bovine serum albumin (BSA) in phosphate-buffered saline (PBS)], and $50 \mu \mathrm{L}$ aliquots were incubated with either anti-pLF or normal rabbit serum (NRS; 1:10 dilution) for $30 \mathrm{~min}$ at $37^{\circ} \mathrm{C}$. After washing with 10 volumes of BSA-PBS buffer, the mammary gland slides were incubated with affinity-purified goat anti-rabbit IgG antibody conjugated to HRP at a dilution of $1: 100$ for $30 \mathrm{~min}$ at $37^{\circ} \mathrm{C}$ and stained with DAB dye. After washing, the slides were observed under a light microscope (Axiovert 135; Carl Zeiss, Germany).

Pup Weight Gains, Duodenum Villous Measurement, and Statistical Analysis. Individual pups in each litter were weighed daily for the first 4 weeks at 9:00 a.m. each day following birth (morning following birth $=$ day 1 ). Weights were plotted with SigmaPlot (SPSS, Chicago, IL). All experimental data are expressed as the mean \pm standard deviation (SD). Intestinal samples were taken on the last day of the experiment. Sections $(1 \mathrm{~cm})$ from five mice per experimental groups were obtained from the duodenum at the apex of the pancreas. Samples were flushed with saline, fixed in $10 \%$ paraformaldehyde, embedded with paraffin, thin-sectioned, and stained with hematoxylineosin. For each intestinal section, 12 randomly selected duodenum villi heights were estimated using Image-Pro-Plus software (Media Cybernetics, Silver Spring, MD). Data were analyzed in the General Linear Models procedures of SAS (SAS Institute, Inc., Cary, NC). A difference between two means was considered to be statistically significant based on $p<0.05(*)$.

\section{RESULTS}

Production of Transgenic Mice Harboring the $\alpha \mathrm{LA}-\mathrm{pLF}$ Hybrid Gene. To generate transgenic mice with the pLF transgene in their genomes capable of expressing the pLF protein in their mammary gland, a DNA construct that carried a $2.0 \mathrm{~kb}$ regulatory sequence of the bovine $\alpha$-lactalbumin $(\alpha \mathrm{LA})$ gene and a $2.0 \mathrm{~kb}$ pLF cDNA sequence (Figure 1A) was first engineered in the cloning vector pCR3. For pronuclear embryo microinjection, the mammary gland-specific expression cassette of the $\alpha$ LA-pLF-bGHpoly(A) transgene was excised from the vector by double digestion with AvrII and XhoI. A total of 515 microinjected pronuclear-stage mouse embryos were transferred into 18 recipient mice. Of 81 potential transgenic founder mice, 14 were identified as being transgenic by the PCR screening. As shown in Figure 1B, a bright 450 bp PCR product was exhibited in some positive transgenic mice (Tg-pLF-1 and TgpLF-19), whereas several PCR detected bands were relatively faint (Tg-pLF-4 and Tg-pLF-8). Mini-gel hybridization (Figure 1C) confirmed that these slight bands contained the $\alpha \mathrm{LA}-\mathrm{pLF}$ transgene in the mouse genomes.

Determination of Transgene Insertion Copy in the Mouse Genomes. To verify the transgene insertion copy in mouse
(A)

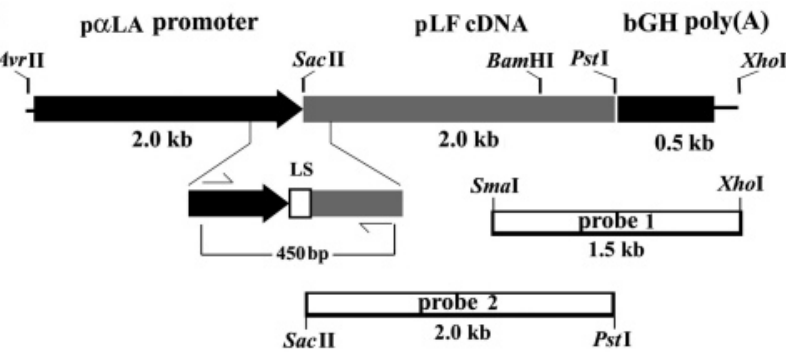

(B)

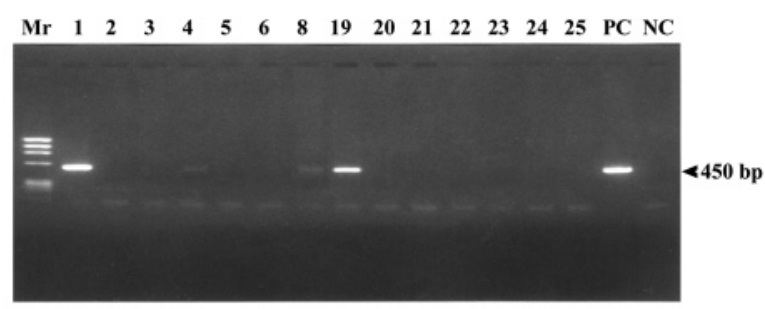

(C)

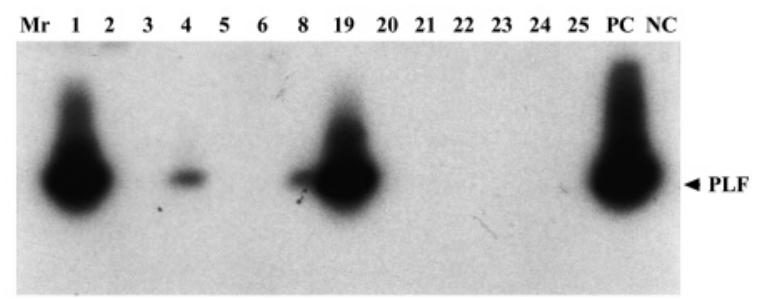

Figure 1. Schematic map of transgene construction and rapid screening of transgenic mice by PCR and mini-gel hybridization. (A) Structure of the $\alpha \mathrm{LA}-\mathrm{pLF}-\mathrm{bGHpA}$ fusion gene. A pair of primer sets for PCR screening and a $1.5 \mathrm{~kb}$ pLF-bGH poly(A) Smal-Xhol fragment as probe 1 for Southern blot hybridization were designed to flank the $5^{\prime}$ - and $3^{\prime}$-ends of pLF cDNA, respectively. LS, leader sequence for secretion signal. (B) Rapid screening of positive transgenic founders by PCR amplification. PC, pCR- $\alpha$ LA-pLF plasmid DNA (positive control); NC, normal mouse DNA (negative control). (C) Mini-gel hybridization to confirm the PCR amplified transgenic bands in the founders of transgenic mice. PCR products in the agarose gel were directly transferred onto a nylon membrane and subjected to hybridization with isotope-labeled $2.0 \mathrm{~kb}$ pLF cDNA (probe 2).

genomes, the inserted gene copy in each cell was quantified by slot-blot analysis. A serial dilution of $\mathrm{pCR}-\alpha \mathrm{LA} / \mathrm{pLF}-38$ plasmid DNA was added to an equal amount $(10 \mu \mathrm{g})$ of non-transgenic mouse DNA to serve as the copy-number standard (Figure 2, lane A) and an input DNA normalization was based on the $\beta$-actin hybridization signal (Figure 2, right). On the basis of this quantification assay, the transgenic founder lines were classified into three groups. The low copy number group (defined as $1-5$ copies per cell) comprised eight transgenic lines including Tg-pLF-4, -7, -8, -19, -38, -48, -50, and -67. The middle copy number group $(5-10$ copies per cell) was composed of three lines including Tg-pLF-56, -76, and -80 . Finally, there were three lines (Tg-pLF-1, -33, and -69) carrying high copy numbers $(15-20$ copies per cell) of the $\alpha \mathrm{LA}-\mathrm{pLF}$ transgene in their genomes (Figure 2).

Analysis of Integration Patterns by Southern Blot Hybridization. The transgene integration patterns and the number of integration sites in these mice were dissected by Southern blots using different restriction enzymes, DraI for transgenecellular junction digestion (Figure 3A) and BamHI for singlecutting within transgene (Figure 3B). Because the transgene was randomly integrated into the mouse genome, the unique flanking sequences could be seen in each integration site and represented a distinct band in DraI-digested Southern blot 


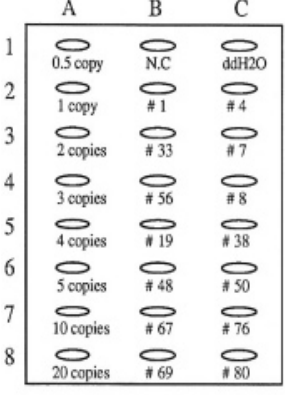

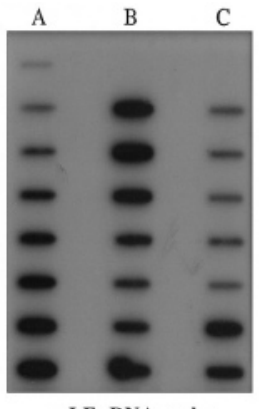

PLF cDNA probe

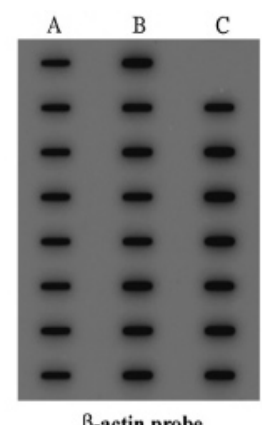

$\beta$-actin probe
Figure 2. Determination of pLF transgene copy number in the genomes of transgenic founders by slot-blot hybridization: (left) slot-blot chart indicating the location of each arrayed DNA sample; (middle) $10 \mu \mathrm{g}$ of genomic DNA samples blotted onto the nitrocellulose membrane and hybridized with the probe 1 (as shown in Figure 1A); (right) filter stripped and rehybridized with a $0.8 \mathrm{~kb}$ fragment of mouse $\beta$-actin gene probe that was used as an internal control. Copy standards were prepared by mixing $10 \mu \mathrm{g}$ of non-transgenic tail DNA with a known amount of transgene plasmid DNA to produce transgene copy standards as shown in lane A. NC, genomic DNA from wild-type non-transgenic mouse was used as a negative control. Results are representative of two experiments.

(A)

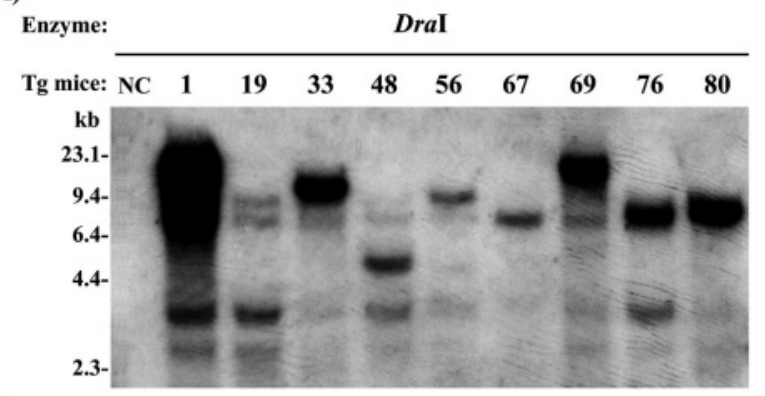

(B)

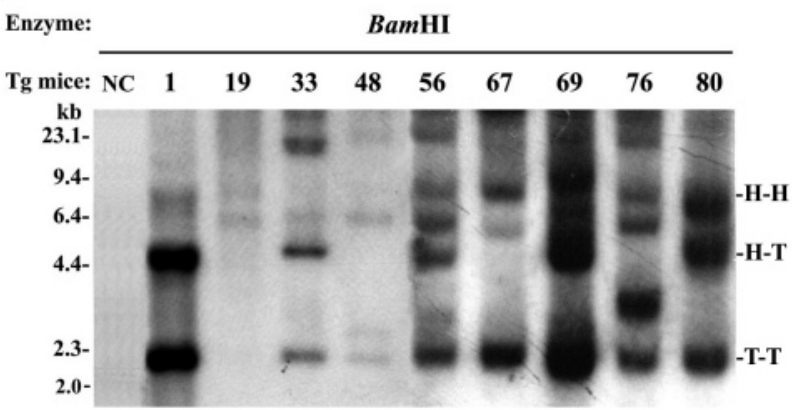

Figure 3. Southern blot analysis of the pLF transgene integration sites and reiteration patterns in transgenic mice. (A) For determination of the number of transgene integration sites, genomic DNA of the pLF transgenic mice was digested with Dral restriction enzyme, blotted onto a nitrocellular filter, and subjected to hybridization with a $1.5 \mathrm{~kb}$ fragment of $3^{\prime}$-end pLF cDNA (probe 1). (B) For determination of transgene reiteration patterns, genomic DNA extracted from different founders of transgenic mouse tails was digested with $\mathrm{BamHI}$ and subjected to probe hybridization. $\mathrm{H}-\mathrm{T}$, headto-tail joining tandem repeats; $\mathrm{T}-\mathrm{T}$, tail-to-tail joining; $\mathrm{H}-\mathrm{H}$, head-to-head joining inverted repeats; NC, normal mouse DNA (negative control). Results are representative of three experiments.

(Figure 3A). The number of integration sites varied from one (such as Tg-pLF-56, -67, and -80) to four (such as Tg-pLF-1 and -19) as judged by the number of transgene-positive DraI bands observed.

The integrity of transgenes and their integration patterns were determined in the BamHI-digested Southern blot analysis. On hybridization using the $1.5 \mathrm{~kb} S m a \mathrm{I}-X h \mathrm{I}$ fragment of porcinespecific $3^{\prime}$-end pLF cDNA sequence as a probe (Figure $3 \mathbf{B}$ ), a $4.5 \mathrm{~kb}$ band with an expected size of the full-length transgene was detected in transgenic mice, Tg-pLF-1, -33, -56, -69, and -80 . The band represented monomeric transgene copies of headto-tail joining $(\mathrm{H}-\mathrm{T})$ tandem repeats (Figure 3B). The 2.2 and $6.8 \mathrm{~kb}$ hybridization bands observed in the blots of most of the transgenic mice were present in tail-to-tail joining ( $\mathrm{T}-\mathrm{T})$ and head-to-head joining $(\mathrm{H}-\mathrm{H})$ inverted repeats, respectively. Different intensities of the hybridization signal were also observed, indicating the presence of different transgene copy numbers in these mice. All genomes of the transgenic mice harboring $\alpha$ LA-pLF DNA presented two to three off-size bands in addition to the predicted transgene junctions. These bands were probably rearranged transgene sequences, some of which were integration sites representing transgene-cellular junctions.

Breeding lines were established from all transgenic founder mice by crossing them with normal ICR mice. The multiple integrated copies of the transgene were stably germ-line transmitted among 9 (5 females and 4 males) of the 14 transgenic founders.

Secretion of pLF into the Milk of Transgenic Mice. To determine the production of recombinant $\mathrm{pLF}$ and to compare the secretion efficiency of pLF among the different transgenic mouse lines, milk was collected from five lines of F0, F5, and F10 female progenies during lactation. These mice were chosen for further examination of the expression of the transgene. Proteins from the milk of non-transgenic controls and transgenic mice were separated by SDS-PAGE and compared with either an HPLC-purified pLF standard or normal sow's milk by Western blot analysis (Figure 4). No porcine LF was detected by a pLF-specific polyclonal antibody in milk from control mice (Figure 4B, lane 2). Bands of different intensities (Figure 4B, lanes 3, 5, and 7) generated from Tg-pLF-33, -56, and -69 from milk of transgenic mice had the same molecular weight as the milk protein found in sow's milk controls. The results suggested that female progenies of these three transgenic lines produced a significant amount of pLF in the milk, whereas the expression level of the other two lines (Tg-pLF-67 and -76) was undetectable by Western analysis (Figure 4B, lanes 4 and 6). Furthermore, the recombinant pLF secreted in the milk of transgenic mice was electrophoretically similar to the native pLF detected in sow's milk, indicating similar physical characteristics of pLF in these two sources.

A more sensitive ELISA protocol was applied to quantify the amounts of pLF secreted in the milk of transgenic mice. Three transgenic mouse lines (Tg-pLF-33, -56, and -69) produced high concentrations of $\mathrm{pLF}(40-106 \mu \mathrm{g} / \mathrm{mL})$ in milk, whereas two transgenic mouse lines, Tg-pLF-67 and -76, produced under $10 \mu \mathrm{g} / \mathrm{mL}$ of pLF (Table 2); such low concentrations were beyond the detection limits of Western blot.

Tissue-Specific Expression of Exogenic pLF in Mammary Glands by Immuno-histochemistry Staining. To further demonstrate tissue-specific expression of the pLF driven by the bovine $\alpha$-LA promoter, numerous tissues derived from the Tg-pLF-33 lactating female mice were subjected to immunohistochemistry staining using the anti-pLF primary antibody. Mammary gland sections showed that the pLF had accumulated at the edges of mammary epithelia as well as within the lumen of mammary acini during the D15 lactating stage in transgenic mice (Figure 5B). There was no detectable pLF signal in sections of lactating non-transgenic mouse mammary gland (Figure 5A) or in the nonlactating mammary gland of transgenic female (Figure 5C). Different tissues from the same lactating 
(A) $\begin{array}{lllllllll} & & 56- & 67- & 69- & 76- & 33- & \\ \text { Mr NC } & 14 & 121 & 132 & 115 & 175 & \text { pLF } & \text { milk } \\ & & & & & & & \end{array}$

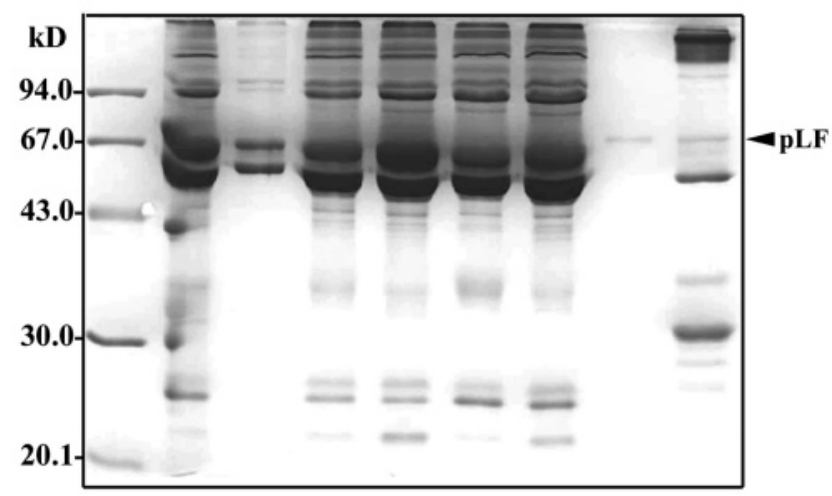

(B)

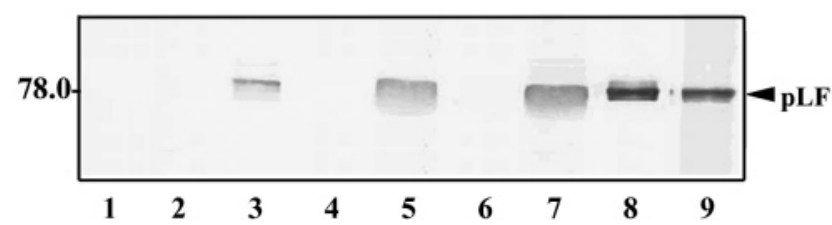

Figure 4. Western blot analysis of pLF protein secretion in skim milk of transgenic mice. (A) Recombinant pLF protein in milk was collected, centrifuged, and subjected to SDS-PAGE in a $12 \%$ polyacrylamide gel: lane 1, protein molecular marker (Mr); lanes $3-7$, milk proteins from different lines of transgenic mice, Tg-pLF-56-14, Tg-pLF-67-121, Tg-pLF69-132, Tg-pLF-76-115, and Tg-pLF-33-175, respectively. (B) Western blotting analysis of pLF protein using a rabbit anti-pLF antibody: lane 2 , milk protein harvested from non-transgenic mice during the lactating stage as a negative control (NC); lane 8, $100 \mathrm{ng}$ of the HPLC-purified pLF (78 kDa) as positive control; lane 9, milk protein harvested from normal sow during the lactating stage (positive control).

stage of transgenic mice, including brain, lung, liver, spleen, heart, muscle, and kidney, were also examined by the same primary antibody. No pLF was found (data not shown). The pLF protein driven by the bovine $\alpha$-lactalbumin promoter and leader sequence was expressed and secreted only in mammary gland tissue.

Growth Performance of Transgenic Pups Monitored by Daily Weight Gains. The effect of pLF-enriched milk during the nursing stage on preweaning growth performance of transgenic mouse pups was measured by monitoring daily weight gain. A total of 30 litters comprising two different generations (F5 and F10) from three groups of newborn mice (Tg-pLF-33 transgenic line, Tg-pLF-69 transgenic line, and normal ICR strain) were measured. Individual pups in a litter were weighed daily during the first four nursing weeks. The results showed that the growth rate of pups from both transgenic lines significantly increased $10-15 \%(p<0.05)$ when compared with that of normal ICR pups (Figure 6A). In milk-feeding experiments, three litters of non-transgenic ICR mouse pups $(n=29)$ were exchanged to feed with the milks from the transgenic mice (Tg-pLF-33 line) as a control to evaluate their growth performance. Data showed a $13.8 \%$ significantly increased body weight gain $(p<0.05)$ when compared with normal ICR pups fed non-transgenic milks (Figure 6B). This good growth performance was due to the pLF-enriched milk, not the transgenic mice themselves. Furthermore, this enhanced growth performance in suckling mice was proportional to the concentration of pLF present in milk from the Tg-pLF-69 ( $10.1 \%$ body weight increase vs $40.2 \pm 6.2 \mathrm{mg} / \mathrm{L} \mathrm{pLF})$ and
Tg-pLF-33 (15.4\% body weight increase vs $106.8 \pm 16.2 \mathrm{mg} / \mathrm{L}$ pLF) transgenic lines (Figure 6B).

Mouse pups suckling pLF-enriched milks from the Tg-pLF33 transgenic female mice had significantly greater villous height in the duodenum than mouse pups suckling normal milks from the wild-type female mice ( $890 \pm 67$ vs $785 \pm 23 \mu \mathrm{m} /$ villous, $p<0.05$; Figure 7).

\section{DISCUSSION}

Our data show that the coupling of a bovine $\alpha$-lactalbumin promoter and leader sequence to a porcine lactoferrin cDNA resulted in the expression and secretion of pLF in the milk of transgenic mice. The highest amount of pLF $(106 \mathrm{mg} / \mathrm{L})$ was found in progenies of mouse line Tg-pLF-33; this high level of pLF production was stably maintained through 10 generations. The pLF level in progenies of line 33 was significantly higher than the levels found in the human LF transgenic mice reported previously (25).

The bovine $\alpha$-lactalbuimn regulatory sequence is more efficient at generating the expression of pLF protein in the milk

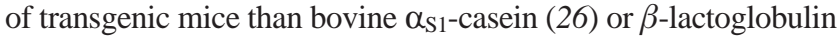
regulatory sequences (27). Use of the $\alpha$ LA 19-aa secretary peptide leader sequence may also have contributed to the high concentration of pLF protein secretion in our study (Figure 1). This characteristic of the bovine $\alpha$ LA gene makes its regulatory elements potentially useful as a mammary expression system in transgenic animals. In contrast to the caseins and $\beta$-lactoglobulin, the production of $\alpha$ LA mRNA increases suddenly at parturition, remains elevated during lactation, and drops sharply at dry-off and during involution (4).

The influence of transgene copy number on the level of gene expression is a complex phenomenon. It is expected that the level of expression would increase with increase in copy number. Experimental evidence, however, has revealed that multiple gene copies frequently lead to gene silencing in plants (28) and in some of the transgenic animals $(4,21)$. After studying the expression levels in the different lines of transgenic mice harboring various copies of $p L F$ transgene (Figure 2), we found that high-copy groups of transgenic lines (Tg-pLF-33 and Tg-pLF-69) continued to show high expression levels, up to the F10 generation, whereas the expression levels in the middlecopy and low-copy groups of transgenic mice were relatively lower (Table 2).

In this study, transgenes were inserted into mouse genomes in large, head-to-tail arrays rather than as single copies (Figure 3). The molecular patterns of integration and reiteration of exogenic DNA sequences in transgenic animals have been clearly elucidated in our previous papers $(4,21)$. Those experiments have revealed that transgene concatenate reiteration involves homologous recombination between multiple copies of the same transgenic DNA molecules, whereas transgene integration basically involves illegitimate recombination involving topoisomerase I cleavage and participation of other nucleotide sequence motifs such as alternating purine-pyrimidine tracks, homopurine runs, and (A-T)-rich regions (2l). The wide range of recombinant pLF protein expression levels in the six different transgenic lines analyzed (Figure $\mathbf{4}$ and Table 2) was probably the consequence of chromosomal integration sites and the reiteration patterns.

Recombinant LF protein has been produced in several other expression systems, such as yeasts, fungi, and insect cells. Results have shown that recombinant LF protein can be expressed under different regulatory sequences, such as those driven by the strong methanol-inducible alcohol dehydrogenase 
Table 2. Characteristics of Porcine Lactoferrin Transgenic Mice

\begin{tabular}{|c|c|c|c|c|c|}
\hline $\begin{array}{l}\text { transgenic } \\
\text { mouse line }\end{array}$ & $\begin{array}{l}\text { transgene } \\
\text { copy no. }\end{array}$ & $\begin{array}{c}\text { no. of } \\
\text { integrated sites }\end{array}$ & $\begin{array}{c}\text { transmission } \\
\text { rate }^{a}(\%)\end{array}$ & generation and lactation ${ }^{b}(\mathrm{~F} / \mathrm{L})$ & $\begin{array}{l}\mathrm{pLF} \text { in milk; }{ }^{c} \mu \mathrm{g} / \mathrm{mL} \\
\text { (no. of mice) }\end{array}$ \\
\hline \multicolumn{6}{|c|}{ (A) High-Copy Group } \\
\hline Tg-pLF-33 & 20 & 2 & 41 & $\mathrm{~F} 1 / \mathrm{L} 1, \mathrm{~F} 1 / \mathrm{L} 2, \mathrm{~F} 5 / \mathrm{L} 1, \mathrm{~F} 5 / \mathrm{L} 2, \mathrm{~F} 10 / \mathrm{L} 1$ & $106.8 \pm 16.2(n=5)$ \\
\hline Tg-pLF-69 & 20 & 3 & & F1/L1, F1/L2, F5/L1, F5/L2, F10/L1 & $40.2 \pm 6.2(n=5)$ \\
\hline \multicolumn{6}{|c|}{ (B) Middle-Copy Group } \\
\hline Tg-pLF-56 & 10 & 1 & 30 & $\mathrm{~F} 1 / \mathrm{L} 1, \mathrm{~F} 1 / \mathrm{L} 2, \mathrm{~F} 5 / \mathrm{L} 1, \mathrm{~F} 5 / \mathrm{L} 2$ & $41.6 \pm 14.3(n=4)$ \\
\hline Tg-pLF-76 & 10 & 2 & & $\mathrm{~F} 1 / \mathrm{L} 1, \mathrm{~F} 1 / \mathrm{L} 2, \mathrm{~F} 5 / \mathrm{L} 1, \mathrm{~F} 5 / \mathrm{L} 2, \mathrm{~F} 10 / \mathrm{L} 1$ & $7.2 \pm 2.5(n=5)$ \\
\hline \multicolumn{6}{|c|}{ (C) Low-Copy Group } \\
\hline Tg-pLF-48 & 2 & 2 & 23 & $\mathrm{~F} 1 / \mathrm{L} 1, \mathrm{~F} 1 / \mathrm{L} 2, \mathrm{~F} 5 / \mathrm{L} 1, \mathrm{~F} 5 / \mathrm{L} 2, \mathrm{~F} 10 / \mathrm{L} 1$ & $10.5 \pm 3.1(n=5)$ \\
\hline Tg-pLF-67 & 4 & 1 & 68 & $\mathrm{~F} 1 / \mathrm{L} 1, \mathrm{~F} 1 / \mathrm{L} 2, \mathrm{~F} 5 / \mathrm{L} 1, \mathrm{~F} 5 / \mathrm{L} 2, \mathrm{~F} 10 / \mathrm{L} 1, \mathrm{~F} 10 / \mathrm{L} 2$ & $8.5 \pm 2.8(n=6)$ \\
\hline
\end{tabular}

${ }^{a}$ Transmission rate $(\%)=$ number of positive transgenic pups/total number of transgenic offspring. ${ }^{b}$ Exogenic $\mathrm{pLF}$ expression in the milks was measured in different generations (F1, F5, and F10) and in two different lactation periods, first lactation (L1) and second lactation (L2). ${ }^{c}$ Expression of pLF protein in the milks of transgenic mice was quantitatively detected by ELISA.

(A) Lactating normal M.G.

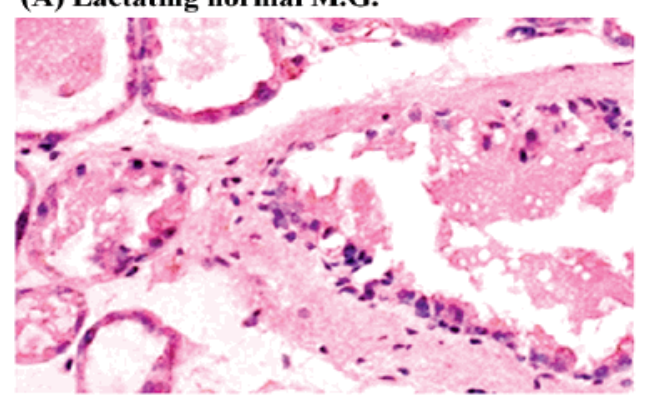

(B) Lactating transgenic M.G.

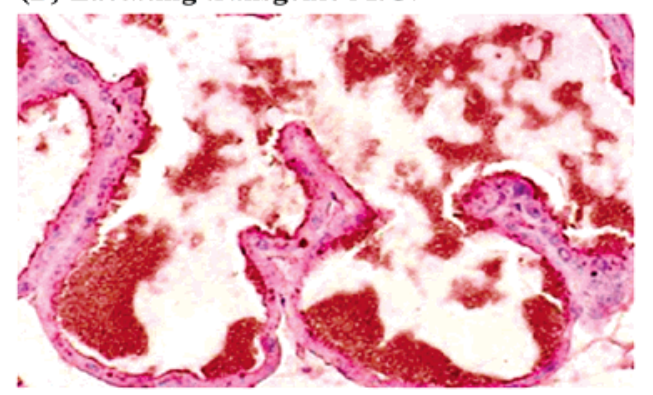

(C) Non-lactating transgenic M.G.

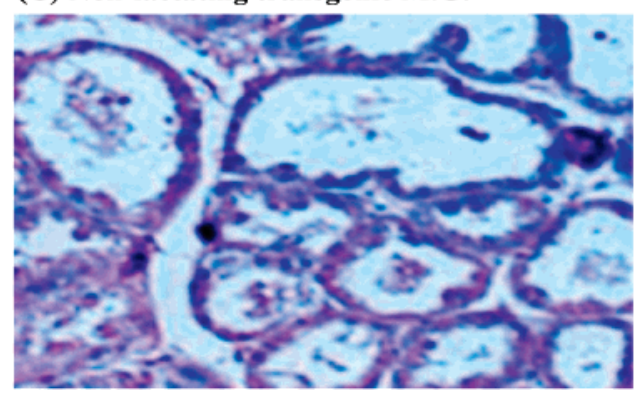

Figure 5. Immuno-histochemistry $(\mathrm{IHC})$ staining of mammary gland tissues from normal mice (A) and F1 progeny of Tg-pLF-33 transgenic mice (B). Mammary glands (M.G.) in the D15 lactating stage were formaldehyde fixed, sliced into $5 \mu \mathrm{m}$ thick sections, and mounted on slides. A mammary gland tissue section from nonlactating stage of a transgenic female was used as control for stage-specific pLF expression (C). Porcine LF protein expression was detected using the anti-pLF-specific primary antibody and HRP-conjugated secondary antibody. Samples were viewed using an Olympus IX71 microscope and DP71 image analyzer (original magnification, $\times 400$ ). The stained $p L F$ in the transgenic mammary gland is shown as red color. Results are representative of two experiments.

promoter (up to $5 \mathrm{mg} / \mathrm{L} \mathrm{rLF}$ in Aspergillus nidulans) (29), the glyceraldehydes-3-phosphate dehydrogenase (G3PD) promoter
(A)

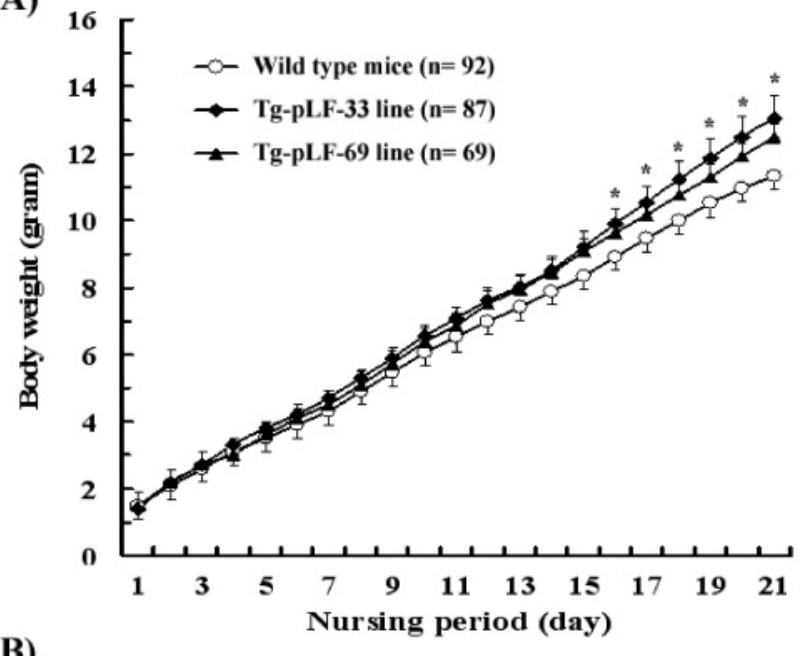

(B)

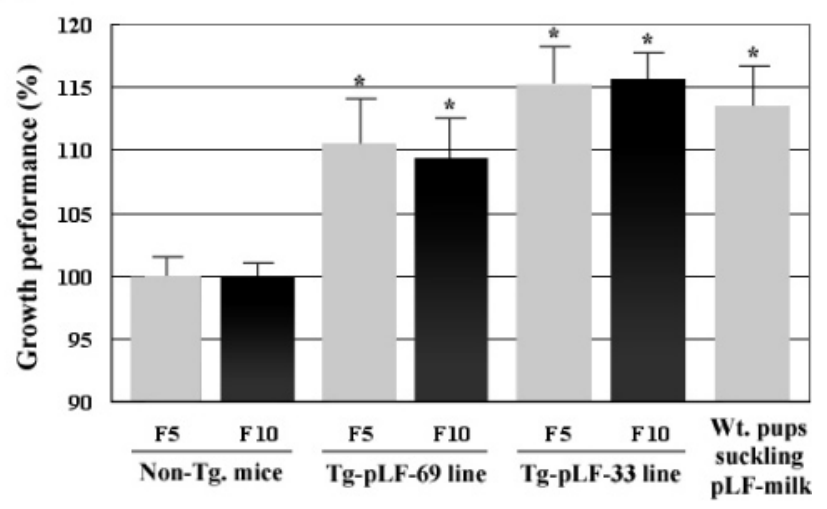

Figure 6. Effects of pLF-enriched protein in the milk of transgenic mice on body weight gain during lactation period. (A) Growth curve of pups during the lactation period among three different groups, one control group of wild-type mice $(n=92)$ and two test groups of transgenic mice, TgpLF-33 line $(n=87)$ and Tg-pLF-69 line $(n=69)$. The pups were weighed between 9:00 and 9:30 a.m. each day during the lactation stage. The weights are presented as mean $\pm S D$. (B) Enhanced growth performance of preweaning mice from different generations (F5 and $\mathrm{F} 10$ ) and different pLF-expressed transgenic mouse lines (Tg-pLF-69 and Tg-pLF-33) compared with the non-transgenic (Non-Tg) mouse lines. Wild-type mouse (Wt.) pups $(n=29)$ feeding with the milks from the transgenic mice (Tg-pLF-33 line) were also applied to evaluate their growth performance. The asterisks represent significant differences $\left({ }^{*}, p<0.05\right)$ when compared with the respective control groups.

(approximately $12 \mathrm{mg} / \mathrm{L} \mathrm{rLF}$ in Pichia pastoris) (30), the yeast chelatin regulatory sequence $(1-2 \mathrm{mg} / \mathrm{lLF}$ in Saccharomyces 
(A)

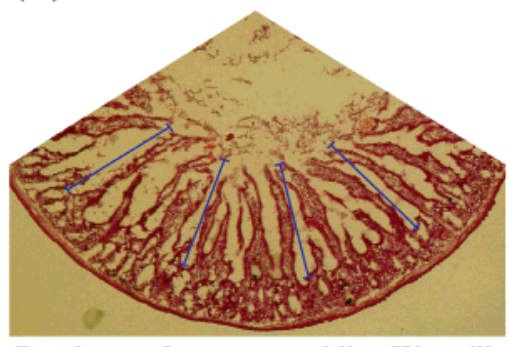

Duodenum from pup suckling Wt. milk

(B)

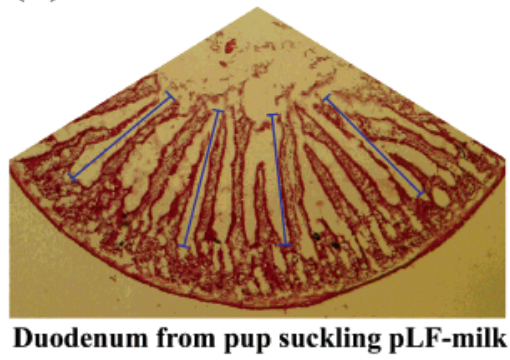

(C)

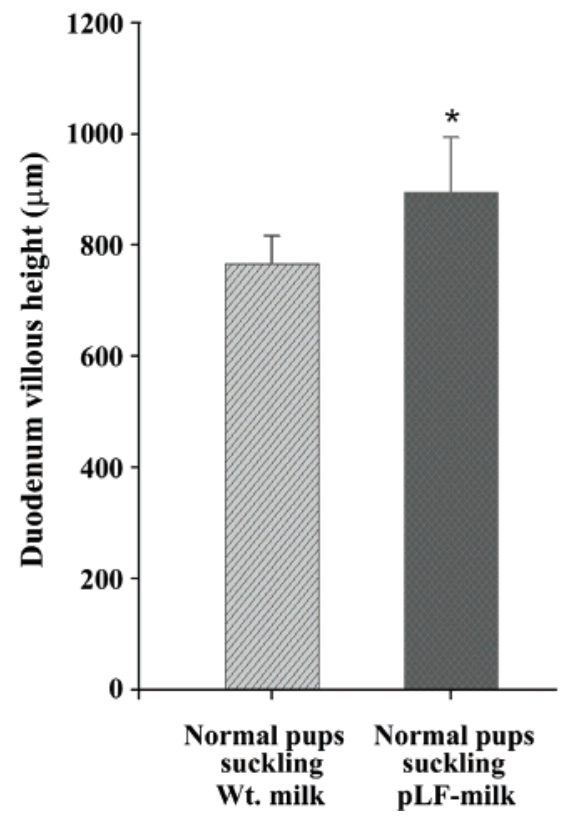

Figure 7. Duodenum histology and villous length measurement of mouse pups suckling wild-type (Wt.) normal milks (A) compared with those suckling pLF-enriched milks derived from transgenic mice (B). For each intestinal section, duodenum villous height was estimated for at least 10 individual villi as shown by the blue lines. (C) The statistical data of duodenum villous height $(\mu \mathrm{m})$ between control and treated groups were presented as mean $\pm \mathrm{SD}$. *,$p<0.05$.

cerevisiae) (31), and the Autographa californica nuclear polyhedrosis virus promoter (approximately $10 \mathrm{mg} / \mathrm{L} \mathrm{N}$-lobe $\mathrm{rLF}$ in insect cells) (32). However, the levels of recombinant LF expression reported in those studies were low, suggesting that antimicrobial active LF might be toxic to yeast and insect host cells during fermentation. On the contrary, our results showed that there were no adverse effects in mammary gland tissue of transgenic animals during lactation (Figure 5).

Extensive in vitro and in vivo studies have shown that LF has antibacterial, antifungal, antiviral, and anti-inflammatory properties. Therefore, LF is postulated to be involved in the innate host defense against infection and severe inflammation, most notable at mucosal surfaces such as those of the gastrointestinal tract (33). Antimicrobial properties of LF include bacteriostasis by iron deprivation (34), bactericidal activity by destabilization of the cell wall $(7,10)$, and antiviral activity by inhibition of viral infection (35). Besides antimicrobial activity, LF has been shown to promote the growth of Bifidobacterium species, the predominant bacteria of the intestinal flora of healthy breast-fed newborns (36). In addition, LF has been shown to promote the growth of intestinal cells both in vitro and in vivo (37), which may be mediated through binding to specific receptors (38). We demonstrated in our transgenic mouse model that the growth rate of animal pups is enhanced by directly feeding the genetically engineered milk containing enriched pLF (Figure 6). Furthermore, enhanced growth performance in suckling mice was proportional to the concentration of $\mathrm{pLF}$ present in the milk (Figure 6B and Table 2). We observed increased villi length in the small intestinal tract of mouse pups suckling pLF-enriched genetically engineered milk from transgenic female (Figure 7). Presumably the increased villi length, and consequently surface area, would facilitate better nutrient digestion and absorption, explaining the improved growth performance.

In conclusion, we have successfully engineered transgenic mice capable of expressing and secreting recombinant $\mathrm{pLF}$ in milk. The experimental pups fed pLF-enriched milk from transgenic mice gained $10-15 \%$ in body weight. This transgenic mouse model for expressing high levels of pLF will be of great value for the mass production of biologically active pLF in transgenic farm animals in the post-antibiotics era.

\section{ACKNOWLEDGMENT}

We thank Dr. Jeffrey Conrad for critically reading the manuscript. We also thank Chung-Yu Lin for assistance in transgenic mouse breeding.

Supporting Information Available: Detailed restriction map of $\alpha \mathrm{LA}-\mathrm{pLF}$ transgene construct and integrated cellular junction and chromosomal integration sites assay of Tg-pLF transgene by fluorescent in situ chromosome hybridization (FISH). This material is available free of charge via the Internet at http://pubs.acs.org.

\section{LITERATURE CITED}

(1) Hirabayashi, M.; Kodaira, K.; Takahashi, R.; Sagara, J.; Suzuki, T.; Ueda, M. Transgene expression in mammary glands of newborn rats. Mol. Reprod. Dev. 1996, 43, 145-149.

(2) Naruse, K.; Yoo, S. K.; Kim, S. M.; Choi, Y. J.; Lee, H. M.; Jin, D. I. Analysis of tissue-specific expression of human type II collagen cDNA driven by different sizes of the upstream region of the $\beta$-casein promoter. Biosci., Biotechnol., Biochem. 2006, 70, 93-98.

(3) Devinoy, E.; Montoliu, L.; Baranyi, M.; Thepot, D.; Hiripi, L.; Fontaine, M. L.; Bodrogi, L.; Bosze, Z. Analysis of the efficiency of the rabbit whey acidic protein gene $5^{\prime}$ flanking region in controlling the expression of homologous and heterologous linked genes. J. Dairy Res. 2005, 72, 113-119.

(4) Chen, C. M.; Wang, C. H.; Wu, S. C.; Lin, C. C.; Lin, S. H.; Cheng, W. T. K. Temporal and spatial expression of biologically active human factor VIII in the milk of transgenic mice driven by mammary-specific bovine $\alpha$-lactalbumin regulation sequences. Transgenic Res. 2002, 11, 257-268.

(5) Niavarani, A.; Dehghanizadeh, S.; Zeinali, S.; Karimi, M.; Magliano, M.; Rassoulzadegan, M. Development of transgenic mice expressing calcitonin as a $\beta$-lactoglobulin fusion protein in mammary gland. Transgenic Res. 2005, 14, 719-727. 
(6) Zheng, J.; Ather, J. L.; Sonstegard, T. S.; Kerr, D. E. Characterization of the infection-responsive bovine lactoferrin promoter. Gene 2005, 353, 107-117.

(7) Chen, H. L.; Lai, Y. W.; Yen, C. C.; Lin, Y. Y.; Lu, C. Y.; Yang, S. H.; Tsai, T. C.; Lin, Y. J.; Lin, C. W.; Chen, C. M. Production of recombinant porcine lactoferrin exhibiting antibacterial activity in methylotrophic yeast, Pichia pastoris. J. Mol. Microbiol. Biotechnol. 2004, 8, 141-149.

(8) Oh, S. M.; Pyo, C. W.; Kim, Y.; Choi, S. Y. Neutrophil lactoferrin upregulates the human p53 gene through induction of NF- $\kappa$ B activation cascade. Oncogene 2004, 23, 8282-8291.

(9) Appelmelk, B. J.; An, Y. Q.; Geerts, M.; Thijs, B. G.; de Boer, H. A.; MacLaren, D. M.; de Graaff, J.; Nuijens, J. H. Lactoferrin is a lipid A-binding protein. Infect. Immun. 1994, 62, 26282632.

(10) Ulvatne, H.; Haukland, H. H.; Olsvik, O.; Vorland, L. H. Lactoferricin B causes depolarization of the cytoplasmic membrane of Escherichia coli ATCC 25922 and fusion of negatively charged liposomes. FEBS Lett. 2001, 492, 62-65.

(11) Singh, P. K.; Parsek, M. R.; Greenberg, E. P.; Welsh, M. J. A component of innate immunity prevents bacterial biofilm development. Nature 2002, 417, 552-555.

(12) Yang, T. S.; Wu, S. C.; Wang, S. R. Serum and milk lactoferrin concentration and the correlation with some blood components in lactating sows. Res. Vet. Sci. 2000, 69, 95-97.

(13) Tomita, M.; Wakabayashi, H.; Yamauchi, K.; Teraguchi, S.; Hayasawa, H. Bovine lactoferrin and lactoferricin derived from milk: production and applications. Biochem. Cell Biol. 2002, 80, 109-112.

(14) Baker, E. N.; Baker, H. M. Molecular structure, binding properties and dynamics of lactoferrin. Cell Mol. Life Sci. 2005, $62,2531-2539$

(15) Thomassen, E. A.; van Veen, H. A.; van Berkel, P. H.; Nuijens, J. H.; Abrahams, J. P. The protein structure of recombinant human lactoferrin produced in the milk of transgenic cows closely matches the structure of human milk-derived lactoferrin. Transgenic Res. 2005, 14, 397-405.

(16) Chen, H. L.; Yen, C. C.; Lu, C. Y.; Yu, C. H.; Chen, C. M. Synthetic porcine lactoferricin with a 20-residue peptide exhibits antimicrobial activity against Escherichia coli, Staphylococcus aureus, and Candida albicans. J. Agric. Food Chem. 2006, 54, $3277-3282$

(17) Wang, Y.; Han, F.; Xu, Z. Developmental gene expression of lactoferrin in duodenum and effect of weaning age on gene expression of lactoferrin in piglets. Arch. Anim. Nutr. 2006, 60, $1-9$.

(18) Hanson, L. A.; Korotkova, M.; Haversen, L.; Mattsby-Baltzer, I.; Hahn-Zoric, M.; Silfverdal, S. A.; Strandvik, B.; Telemo, E. Breast-feeding, a complex support system for the offspring. Pediatr. Int. 2002, 44, 347-352.

(19) Lee, W. J.; Farmer, J. L.; Hilty, M.; Kim, Y. B. The protective effects of lactoferrin feeding against endotoxin lethal shock in germfree piglets. Infect. Immun. 1998, 66, 1421-1426.

(20) Chu, R. M.; Wang, S. R.; Weng, C. N.; Pursel, V. G. Isolation and characterization of porcine milk lactoferrin. Am. J. Vet. Res. 1993, 54, 1154-1159.

(21) Chen, C. M.; Choo, K. B.; Cheng, W. T. K. Frequent deletions and sequence aberrations at the transgene junctions of transgenic mice carrying the papillomavirus regulatory and the SV40 TAg gene sequences. Transgenic Res. 1995, 4, 52-59.

(22) Cheng, W. T. K.; Lee, C. H.; Hung, C. M.; Chang, T. J.; Chen, C. M. Growth hormone gene polymorphisms and growth performance traits in Duroc, Landrace and Tao-Yuan pigs. Theriogenology 2000, 54, 1225-1237.

(23) Chen, H. L.; Yen, C. C.; Tsai, T. C.; Yu, C. H.; Liou, Y. J.; Lai, Y. W.; Wang, M. L., Chen, C. M. Production and characterization of human extracellular superoxide dismutase (ECSOD) in the methylotrophic yeast Pichia pastoris. J. Agric. Food Chem. 2006, 54, 8041-8047.
(24) Cheng, W. T. K.; Chen, B. C.; Chiou, S. T.; Chen, C. M. Use of nonautologous microencapulated fibroblasts in growth hormone gene therapy to improve growth of midget swine. Hum. Gene Ther. 1998, 9, 1995-2003.

(25) Platenburg, G. J.; Kootwijk, E. P. A.; Kooiman, P. M.; Woloshuk, S. L.; Nuijens, J. H.; Krimpenfort, P. J. A.; Pieper, F. R.; de Boer, H. A.; Strijker, R. Expression of human lactoferrin in milk of transgenic mice. Transgenic Res. 1994, 3, 99-108.

(26) Nuijens, J. H.; van Berkel, P. H. C.; Geerts, M. E. J.; Hartevelt, P. P.; de Boer, H. A.; van Veen, H. A.; Pieper, F. R. Characterization of recombinant human lactoferrin secreted in milk of transgenic mice. J. Biol. Chem. 1997, 28, 88028807.

(27) Baumrucker, C. R.; Saurer, S.; Blum, J. W.; Jungi, T.; Friis, R. R. Lactoferrin (Lf): retinoid interactions in the mammary glands of transgenic mice overexpressing human Lf. Mol. Cell. Endocrinol. 2006, 251, 56-66.

(28) Kathuria, H.; Mohanty, A.; Tyagi, A. K. Analysis of inheritability and expression profile of single and multi-copy transgene in rice over generations. J. Plant Biochem. Biotechnol. 2003, 12, 103107.

(29) Ward, P. P.; May, G. S.; Headon, D. R.; Conneely, O. M. An inducible expression system for the production of human lactoferrin in Aspergillus nidulans. Gene 1992, 122, 219223.

(30) Wang, S. H.; Yang, T. S.; Lin, S. M.; Tsai, M. S.; Wu, S. C.; Mao, S. J. Expression, characterization, and purification of recombinant porcine lactoferrin in Pichia pastoris. Protein Express. Purif. 2002, 25, 41-49.

(31) Liang, Q.; Richardson, T. Expression and characterization of human lactoferrin in yeast Saccharomyces cerevisiae. J. Agric. Food Chem. 1993, 41, 1800-1807.

(32) Nakamura, I.; Watanabe, A.; Tsunemitsu, H.; Lee, N. Y.; Kumura, H.; Shimazaki, K. I.; Yagi, Y. Production of recombinant bovine lactoferrin $\mathrm{N}$-lobe in insect cells and its antimicrobial activity. Protein Express. Purif. 2001, 21, 424-431.

(33) Nuijens, J. H.; van Berkel, P. H.; Schanbacher, F. L. Structure and biological actions of lactoferrin. J. Mammary Gland Biol. Neoplasia 1996, 1, 285-295.

(34) Ellison, R. T., 3rd. The effects of lactoferrin on Gram-negative bacteria. Adv. Exp. Med. Biol. 1994, 357, 71-90.

(35) Ikeda, M.; Nozaki, A.; Sugiyama, K.; Tanaka, T.; Naganuma, A.; Tanaka, K.; Sekihara, H.; Shimotohno, K.; Saito, M.; Kato, $\mathrm{N}$. Characterization of antiviral activity of lactoferrin against hepatitis $\mathrm{C}$ virus infection in human cultured cells. Virus Res. 2000, 66, 51-63.

(36) Petschow, B. W.; Talbott, R. D. Response of bifidobacterium species to growth promoters in human and cow milk. Pediatr. Res. 1991, 29, 208-213.

(37) Zhang, P.; Sawicki, V.; Lewis, A.; Hanson, L.; Nuijens, J. H.; Neville, M. C. Human lactoferrin in the milk of transgenic mice increases intestinal growth in ten-day-old suckling neonates. Adv. Exp. Med. Biol. 2001, 501, 107-113.

(38) Ashida, K.; Sasaki, H.; Suzuki, Y. A.; Lonnerdal, B. Cellular internalization of lactoferrin in intestinal epithelial cells. Biometals 2004, 17, 311-315.

Received for review December 28, 2006. Revised manuscript received March 31, 2007. Accepted April 2, 2007. This research was supported in part by Grants NSC-95-2313-B-005-012 and NSC-93-2313-B-005023 from the National Science Council, Republic of China, and Grant COA-95-6.2.1-U1(9) from the Council of Agriculture. 